\title{
Transmit the heat of rivers to surface seawater
}

\author{
Dongfang Yang ${ }^{1,2,}$, ${ }^{2}$ inzhenWei ${ }^{1}$, Ming Feng ${ }^{1}$, Shengjun Zhang ${ }^{1}$, Danfeng Yang ${ }^{3}$ \\ ${ }^{1}$ School of International Economics, Shaanxi Institute of International Trade \& commerce, Xi'an 712046, China; \\ ${ }^{2}$ North China Sea Environmental Monitoring Center, SOA, Qingdao 266033, China; \\ ${ }^{3}$ The Fu Foundation School of Engineering and Applied Science, Columbia University, 10025, USA
}

\begin{abstract}
Based on the survey materials of the waters of Jiaozhou Bay in April and August 1981, this article studies the water temperature and horizontal distribution in the surface waters of Jiaozhou Bay. The results have showed that the water temperature ranged within $7.52-30.90^{\circ} \mathrm{C}$ in April and August, and the length of interval of water temperature was $23.38^{\circ} \mathrm{C}$. The water temperature of the ocean was above $7.00^{\circ} \mathrm{C}$. It indicated that the water temperature of the entire water body of Jiaozhou Bay was relatively high in April and August, in terms of the changes of water temperature. In April, the water temperature in the water body of Jiaozhou Bay ranged within $7.52-13.70^{\circ} \mathrm{C}$, and the length of temperature interval was $6.18^{\circ} \mathrm{C}$. In Jiaozhou Bay, from the northeastern coastal waters along the northern coastal waters to the northwestern coastal waters, the range of water temperature changes was $12.82-13.70^{\circ} \mathrm{C}$, and the interval length of seawater temperature changes was $0.88^{\circ} \mathrm{C}$. From the northern area to the southern area, the range of water temperature changes was $7.52-13.70^{\circ} \mathrm{C}$, and the interval length of seawater temperature was $6.18^{\circ} \mathrm{C}$. In August, the range of water temperature changes was $24.60-30.90^{\circ} \mathrm{C}$, and the interval length of seawater temperature was $6.30^{\circ} \mathrm{C}$. In the eastern area of Jiaozhou Bay, the water temperature in the coastal waters of the estuary of Jiaozhou Bay was $30.90^{\circ} \mathrm{C}$, forming a high temperature area. In the coastal waters of Jiaozhou Bay from the northwest to the north, the range of water temperature changes was $27.32-27.37^{\circ} \mathrm{C}$ and the interval length of seawater temperature was $0.05^{\circ} \mathrm{C}$. In April and August, the increase of water temperature in the coastal waters from the northeast along the north to the northwest of Jiaozhou Bay was mainly caused by the shortwave radiation from the sun and sky and the longwave radiation from the atmosphere which continuously offered heat to the seawater. In April, it formed a circular water area with low temperature centered with the central water area of Jiaozhou Bay, whose water temperature ranged within $7.52-8.51^{\circ} \mathrm{C}$. Thus, there was no heat source to provide heat to the central waters of Jiaozhou Bay, resulting a loop-locked low water temperature area in the center of the bay. In August, in the eastern part of Jiaozhou Bay, that is, the coastal waters in the estuary of Haibo River, the water temperature reached a relatively high value, $30.90^{\circ} \mathrm{C}$. The source of the increase in water temperature was the transportation of heat from Haibo River, which transferred the heat of the river to the surface seawater.
\end{abstract}

\section{Introduction}

The ocean occupies $71 \%$ of the earth's surface area. At the same time, the heat capacity of seawater greatly exceeds the heat capacity of land and air. Therefore, the ocean plays a great role in climate regulation on the entire earth [1-10]. This paper studies the changes in water temperature and high-temperature water area in the coastal waters, which can provide important help for protecting the marine environment and maintaining sustainable ecological development. Based on the survey data in 1981, the author has analyzed the water temperature, horizontal distribution, and the changes of sources in the water body of Jiaozhou Bay, and has studied the water temperature in the water body of Jiaozhou Bay, the changing process of sources and the source quantity, which provides a scientific background for the comprehensive analysis of the sources and the high temperature area and a theoretical basis for the change of water temperature and its impact on the environment.

\section{Survey waters, materials and methods}

\subsection{Natural environment of Jiaozhou Bay}

Jiaozhou Bay is located in the southern part of Shandong Peninsula. Its geographical position is between $120^{\circ} 04^{\prime}-120^{\circ} 23^{\prime} \mathrm{E}$ and $35^{\circ} 58^{\prime}-36^{\circ} 18^{\prime} \mathrm{N}$. It is bounded by the line connecting Tuan Island and Xuejia Island and is connected to the Yellow Sea. With an area of about $446 \mathrm{~km}^{2}$ and an average water depth of about $7 \mathrm{~m}$, it is a typical semi-enclosed bay. There are more than a dozen

\footnotetext{
adfyang_dfyang@126.com
} 
rivers entering the sea in Jiaozhou Bay, among which the Dagu River, Yang River and the Haibo River, Licun River and Loushan River in Qingdao City with larger runoff and sand content. These rivers are all seasonal rivers, and the river hydrological characteristics have obvious seasonal changes $[11,12]$.

\subsection{Materials and methods}

The survey data of water temperature in the waters of Jiaozhou Bay in April and August 1981 used in this study are provided by the North Sea Monitoring Center of the State Oceanic Administration. In April, taking water samples from 30 stations: A1, A2, A3, A4, A5, A6, $\mathrm{A} 7, \mathrm{~A} 8, \mathrm{~B} 1, \mathrm{~B} 2, \mathrm{~B} 3, \mathrm{~B} 4, \mathrm{~B} 5, \mathrm{C} 1, \mathrm{C} 2, \mathrm{C} 3, \mathrm{C} 4, \mathrm{C} 5, \mathrm{C} 6, \mathrm{C} 7$, C8, D1, D2, D3, D4, D5, D6, D7, D8, D9. In August, taking water samples from 29 stations: A1, A2, A3, A4, A5, A6, A7, A8, B1, B3, B4, B5, C1, C2, C3, C4, C5, C6, C7, C8, D1, D2, D3, D4, D5, D6, D7, D8, D9 (Figure 1). Water samples were taken according to the water depth (surface and bottom layers were taken when the depth $>10 \mathrm{~m}$, and only the surface layer was taken when the depth $<10 \mathrm{~m}$ ) for investigation and sampling. The survey of water temperature in Jiaozhou Bay water body was carried out according to the national standard method, which was recorded in the national "Marine Monitoring Code" (1991) [13].

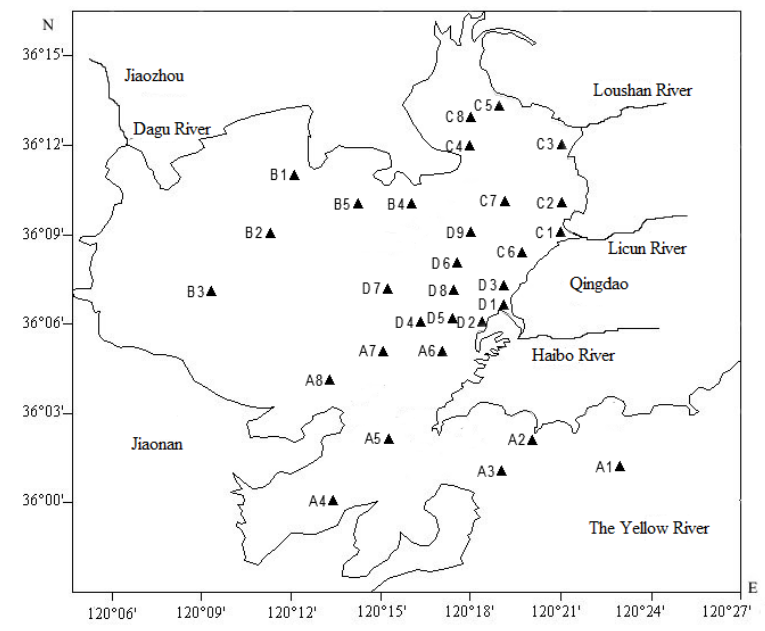

Fig.1 Investigate sites of Jiaozhou Bay

\section{Results}

\subsection{Water temperature}

In April and August, the range of water temperature changes in the waters of Jiaozhou Bay was 7.52-30.90 ${ }^{\circ} \mathrm{C}$, and the interval length of water temperature changes was $23.38^{\circ} \mathrm{C}$. In April, the water temperature of seawater was very low, whose variation range was $7.52-13.70^{\circ} \mathrm{C}$. In August, the water temperature in the surface water body was markedly increased to very high, whose variation range was $24.60-30.90^{\circ} \mathrm{C}$. Therefore, the variation range of the water temperature in the water body of Jiaozhou Bay was $7.52-30.90^{\circ} \mathrm{C}$ in April and August. The water temperature reached $7.00^{\circ} \mathrm{C}$ or above, and the interval length of the water temperature changes was $23.38^{\circ} \mathrm{C}$. It indicated that in April and August, the water temperature in the entire waters of Jiaozhou Bay was relatively high, the variation of water temperature was relatively large, and the increase of water temperature was fairly fast (Table 1).

Tab.1 The surface water temperature in Jiaozhou bay in April and August

\begin{tabular}{|c|c|c|}
\hline Time & April & August \\
\hline Seawater temperature $/{ }^{\circ} \mathrm{C}$ & $7.52-13.70$ & $24.60-30.90$ \\
\hline
\end{tabular}

\subsection{Horizontal distribution}

In April, in the northeast of Jiaozhou Bay, at station C3 in the coastal waters of the estuary of Loushan River, at station C5 in the northeastern coastal waters of Jiaozhou Bay, and at station B1 in the northwestern coastal waters, that is, in the northeastern waters of Jiaozhou Bay along the northern coastal waters to the northwestern coastal waters, the water temperature reached relatively high value, $12.82-13.70^{\circ} \mathrm{C}$, and a high temperature area was formed centered with the northern coastal waters, where a series of parallel lines with different gradients from the north to the south of the bay was appeared. The water temperature gradually decreased from $12.82 \sim 13.70^{\circ} \mathrm{C}$ in the center to $8.11^{\circ} \mathrm{C}$ in the central waters of the bay (Figure 2). At station D7 in the central waters of the bay, it formed a low temperature area with the station D7 as the center, covering the circular water area formed by A7 and $\mathrm{D} 4$, where the water temperature reached the low value within $7.52-8.51^{\circ} \mathrm{C}$. In this way, a loop-locked low-temperature area appeared in the central waters of the bay, and the temperature in this low-temperature area was between $7.52^{\circ} \mathrm{C}$ and $8.51^{\circ} \mathrm{C}$ (Figure 2).

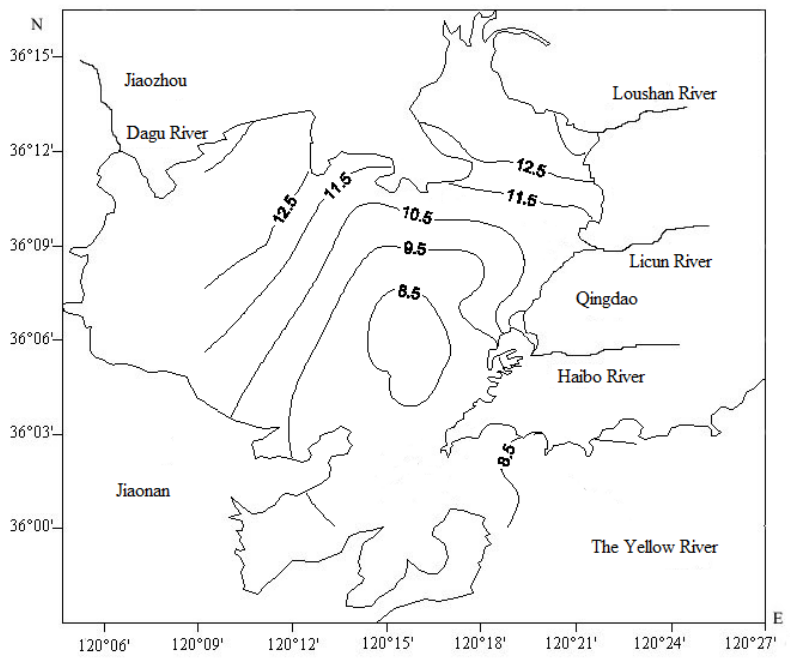

Fig.2 Water temperature distribution in the surface waters of Jiaozhou Bay in April 1981

In August, in the east of Jiaozhou Bay, at station D1 in the coastal waters of the estuary of Haibo River, the water temperature reached a relatively high value, $30.90^{\circ} \mathrm{C}$, and a high temperature area was formed centered with the coastal waters of the estuary of Haibo River, where a series of semi-concentric circles with 
different gradients was appeared. The water temperature gradually decreased from $30.90^{\circ} \mathrm{C}$ in the center to $25.64^{\circ} \mathrm{C}$ in the central waters of the bay (Figure 3 ). At station B1 in the northwestern central waters of the bay, and at station B4 in the northern coastal waters, that is, in the coastal waters from northwest to the west, it formed a high temperature area with the coastal waters from the northwest to the north as the center, forming a series of parallel lines with different gradients, where the water temperature reached relatively high value between $27.32-27.37^{\circ} \mathrm{C}$. The water temperature decreased along the gradients from the center, $27.32-27.37^{\circ} \mathrm{C}$, to the central water of the bay, $25.64^{\circ} \mathrm{C}$ (Figure 3 ).

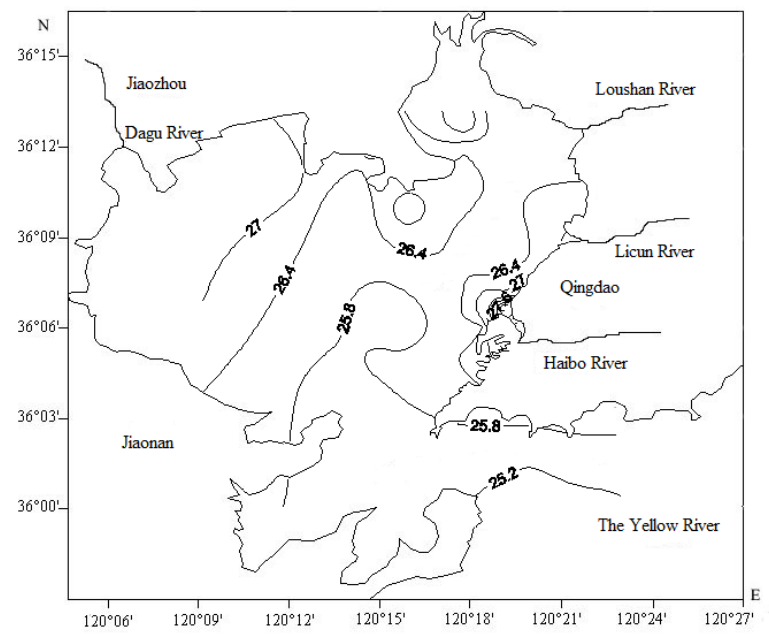

Fig.3 Water temperature distribution in the surface waters of Jiaozhou Bay in August 1981

\section{Discussion}

\subsection{The regional changes in water temperature}

In April and August, the variation range of water temperature in the water body of Jiaozhou Bay was $7.52-30.90^{\circ} \mathrm{C}$. From April to August, the water temperature was above $7.00^{\circ} \mathrm{C}$. In addition, the interval of the variation range of the water temperature was $23.38^{\circ} \mathrm{C}$. It indicated that the water temperature of the entire water body of Jiaozhou Bay was relatively high in April and August, with large variation and fast increase in the water temperature.

In April, the variation range of water temperature in the water body of Jiaozhou Bay was $7.52-13.70^{\circ} \mathrm{C}$, and the interval length of the changes of water temperature was $6.18^{\circ} \mathrm{C}$, which indicated that the water temperature in the waters of Jiaozhou Bay was low, and had small changes. There was a relatively high temperature area in the waters of Jiaozhou Bay, where the changes of water temperature was small. In the coastal waters from the northeast along the north to the northwest, the variation range of water temperature was $12.82-13.70{ }^{\circ} \mathrm{C}$, and the interval length was $0.88^{\circ} \mathrm{C}$, which demonstrated that the water temperature was relatively high and had small changes in the northeastern coastal waters along the northern coastal waters to the northwestern coastal waters. The variation range of water temperature was
7.52-13.70 ${ }^{\circ} \mathrm{C}$ from the north to the south of the bay with the interval length of $6.18^{\circ} \mathrm{C}$. It presented that the water temperature had relatively big changes from high to low and from the north to the south of the bay.

In August, the variation range of water temperature in the water body of Jiaozhou Bay was $24.60-30.90^{\circ} \mathrm{C}$, and the interval length of the changes of water temperature was $6.30^{\circ} \mathrm{C}$, which indicated that the water temperature in the waters of Jiaozhou Bay was very high, and had small changes. In the east of Jiaozhou Bay, there was a relatively high temperature area in the coastal waters of the estuary of Haibo River, where the water temperature reached $30.90^{\circ} \mathrm{C}$. In the coastal waters from the northwest to the north, the variation range of water temperature was $27.32-27.37^{\circ} \mathrm{C}$, and the interval length was $0.05^{\circ} \mathrm{C}$, which demonstrated that the water temperature was relatively high with small changes from the northwestern coastal waters to the northern coastal waters.

\subsection{Sources}

The rise in water temperature is mainly caused by short-wave radiation from the sun and the sky and long-wave radiation from the atmosphere to continuously provide heat to the seawater, and it is provided at all times throughout the year. In addition, the heat conducted by the air to the sea and the heat brought by the ocean currents provide a source of heat for the seawater.

In April, in the coastal waters of Jiaozhou Bay from the northeast along the north to the northwest, the water temperature reached $12.82-13.70^{\circ} \mathrm{C}$, forming a high temperature area with the northern coastal waters as the center. The rise in water temperature was sourced from the short-wave radiation from the sun and the sky, the long-wave radiation from the atmosphere, and the heat transferred from the air to the surface seawater. After the winter, with the increase of solar radiation, the surface seawater temperature gradually rose. The coastal waters in the northeast, north and northwest were relatively shallow, with a water depth of 2.4 to 3.5 meters. In this way, after entering April, the water temperature started to rise from the shallower waters. In Jiaozhou Bay, it formed a low temperature area centered with the central waters of station D7 and covering the circular water area formed by $\mathrm{A} 7$ and $\mathrm{D} 4$, where the water temperature reached the low value of $7.52-8.51^{\circ} \mathrm{C}$. In this way, there was no heat source to provide heat to the central waters of the bay, resulting in a loop-locked low temperature area in the center of the bay (Figure 2).

In August, in the coastal waters of Jiaozhou Bay from the northwest to the north, the water temperature reached $27.32-27.37^{\circ} \mathrm{C}$, forming a high temperature area with the coastal waters from the northwest to north as the center. The rise in water temperature was sourced from the short-wave radiation from the sun and the sky, the long-wave radiation from the atmosphere, and the heat transferred from the air to the surface seawater. As solar radiation continued to increase, the surface seawater temperature gradually rose. At the same time, in August, the temperature was very high, and the heat transferred 
from the air to the seawater further increased. In this way, the surface seawater temperature rose further, and the area of rising water temperature further expanded, resulting the entire waters of Jiaozhou Bay were in a high temperature area. In the eastern part of Jiaozhou Bay, in the coastal waters of the estuary of Haibo River, the water temperature reached a high value of $30.90^{\circ} \mathrm{C}$. A high temperature area was formed centered with the coastal waters of the estuary of Haibo River. The source of the increase in water temperature was the heat transfer from the Haibo River to the surface seawater. Thus, the high temperature area of the surface seawater was in the coastal waters of the estuary of Haibo River.

\section{Conclusion}

The water temperature ranged within $7.52-30.90^{\circ} \mathrm{C}$ in April and August, and the length of interval of water temperature was $23.38^{\circ} \mathrm{C}$. The water temperature of the ocean was above $7.00^{\circ} \mathrm{C}$. It indicated that the water temperature of the entire water body of Jiaozhou Bay was relatively high in April and August, in terms of the changes of water temperature.

In April, the variation range of water temperature in the water body of Jiaozhou Bay was $7.52-13.70^{\circ} \mathrm{C}$, and the interval length of the changes of water temperature was $6.18^{\circ} \mathrm{C}$, which indicated that the water temperature in the waters of Jiaozhou Bay was low, and had small changes. In the coastal waters from the northeast along the north to the northwest, the variation range of water temperature was $12.82-13.70{ }^{\circ} \mathrm{C}$, and the interval length was $0.88^{\circ} \mathrm{C}$. The variation range of water temperature was $7.52-13.70{ }^{\circ} \mathrm{C}$ from the north to the south of the bay with the interval length of $6.18^{\circ} \mathrm{C}$.

In August, the variation range of water temperature in the water body of Jiaozhou Bay was $24.60-30.90^{\circ} \mathrm{C}$, and the interval length of the changes of water temperature was $6.30^{\circ} \mathrm{C}$, which indicated that the water temperature in the waters of Jiaozhou Bay was very high, and had small changes. In the east of Jiaozhou Bay, there was a relatively high temperature area in the coastal waters of the estuary of Haibo River, where the water temperature reached $30.90^{\circ} \mathrm{C}$. In the coastal waters from the northwest to the north, the variation range of water temperature was $27.32-27.37^{\circ} \mathrm{C}$, and the interval length was $0.05^{\circ} \mathrm{C}$.

In April, in the coastal waters of Jiaozhou Bay from the northeast along the north to the northwest, the water temperature reached $12.82-13.70^{\circ} \mathrm{C}$, forming a high temperature area with the northern coastal waters as the center. In August, in the coastal waters of Jiaozhou Bay from the northwest to the north, the water temperature reached $27.32-27.37^{\circ} \mathrm{C}$, forming a high temperature area with the coastal waters from the northwest to north as the center. Thus, in April and August, the rise in water temperature was mainly caused by short-wave radiation from the sun and the sky and long-wave radiation from the atmosphere to continuously provide heat to the seawater, and it is provided at all times throughout the year. In addition, the heat conducted by the air to the sea and the heat brought by the ocean currents provide a source of heat for the seawater.

In April, it formed a low temperature area centered with the central waters of station D7 and covering the circular water area formed by $\mathrm{A} 7$ and $\mathrm{D} 4$, where the water temperature reached the low value of $7.52-8.51{ }^{\circ} \mathrm{C}$. In this way, there was no heat source to provide heat to the central waters of the bay, resulting in a loop-locked low temperature area in the center of the bay.

In August, in the east of Jiaozhou Bay, there was a relatively high temperature area in the coastal waters of the estuary of Haibo River, where the water temperature reached $30.90^{\circ} \mathrm{C}$. The source of the increase in water temperature was the heat transfer from the Haibo River to the surface seawater.

\section{Acknowledgement}

This research was sponsored by Doctoral Degree Construction Library of Guizhou Nationalities University, Research Projects of Guizhou Nationalities University ([2014]02), Research Projects of Guizhou Province Ministry of Education (KY [2014] 266), Research Projects of Guizhou Province Ministry of Science and Technology (LH [2014] 7376).

\section{References}

1. Department of Ocean Thermology. Ocean University of China. Oceanography [M]. Qingdao: China Ocean University Press, 1980, 1-335.

2. Ming Yang, Dongxing Xia, Dongqi Gu, Zou Xue, Aiping Feng. Geographic Environmental Evolution in the Qingdao Coastal Area Under the Influence of Global Change [J]. Advances in Marine Science, 2005, 23(3): 289-296.

3. Dongfang Yang, Zhenqing Miao. Marine Bay Ecology (Volume 1) [M]. Beijing: China Ocean Press, 2010, 1-320.

4. Dongfang Yang, Zhenhui Gao. Marine Bay Ecology (Volume 2) [M]. Beijing: China Ocean Press, 2010, $1-330$.

5. Yang Dongfang, Gao Zhenhui, Sun Peiyan, Zhao Sheng, Zhang Youchi. Silicon limitation on primary production and its destiny in Jiaozhou Bay, ChinaVI The ecological variation process of the phytoplankton [J]. Chin. J. Oceanol. Limnol. 2006, 24(2): 186-203.

6. Yang Dongfang, Gao Zhenhui, Yang Yingbin, Sun Peiyan, Wang Xingping. Silicon limitation on primary production and its destiny in Jiaozhou Bay, ChinaVII The Complementary mechanism of the earth ecosystem [J]. Chin. J. Oceanol. Limnol. 2006, 24(4): 401-412.

7. Dongfang Yang, Zhenhui Gao, Jie Qin, Suxia Huo, Zhongqiang Li. Complementary Mechanism of Nutrient Silicon in Earth Ecosystem [J]. Advances in Marine Science, 2006, 24 (4): 407-412.

8. Dongfang Yang, Zhenhui Gao, Yuan Ma, Peiyan Sun, Yingbin Yang. Influence of environmental 
change on marine biological resources in Jiaozhou Bay [J]. Marine Environmental Science, 2006, 25 (4): 39-42.

9. Dongfang Yang, Jianping $\mathrm{Wu}$, Yanfeng $\mathrm{Qu}$, Jun $\mathrm{Hu}$, Yanrong Zhou. Complementary Mechanism of Air and Water Temperatues in the Earth Ecosystem [J]. Advances in Marine Science, 2007, 25 (1): 117-122.

10. Dongfang Yang, Zhenhui Gao, Wenfeng Li, Zijiang $\mathrm{Yu}$, Changjiang Huang. Study on the Impact of Marine Ecological Change on Climate and Its Associations with Crop Planting [J]. Journal of Modern Academic Research, 2007, 7:104-109.
11. YANG D F, CHEN Y, GAO Z H, et al. SiLicon Limitation on primary production and its destiny in Jiaozhou Bay, China IV transect offshore the coast with estuaries [J]. Chin. J. Oceanol. Limnol. 2005, 23(1): 72-90.

12. Dongfang Yang, Fan Wang, Zhenhui Gao, et al. Ecological Phenomena of Phytoplankton in Jiaozhou Bay [J]. Marine Science, 2004, 28 (6): 71-74.

13. State Oceanic Administration. The Specification for Marine Monitoring [Z]. Beijing: China Ocean Press, 1991. 